\title{
“新工科”背景下广西大学化学类专业创新型人才培养的 研究与实践
}

周立亚 ${ }^{*}$ 段文贵，何熙璞，刘丽，许雪棠，徐远金，王凡，陈培灿，郑礼婷，李香， 王艺频，杨红

广西大学化学化工学院, 南宁 530004

摘要: 面对新产业、新技术和新业态的快速发展需求, 广西大学化学类专业以创新型人才培养为目标, 与地方经济 社会发展紧密结合, 按照新工科理念对化学类专业进行特色建设, 推动具有鲜明区域特征的化学类专业特色化发展。 通过专业人才培养方案修订, 积极探索 “校企、科教、本硕” “三结合” 的人才培养模式改革, 优化课程教学内容, 开展创新型人才培养，对以新工科理念对化学类专业进行特色方向建设具有一定的指导意义。

关键词: 化学类专业; 新工科; 教学改革; 创新实践

中图分类号: G64; O6

\section{Cultivation Innovative Talents of Chemistry Specialty in Guangxi University for Guidance of the Emerging Engineering Education}

\author{
Liya Zhou ${ }^{*}$, Wengui Duan, Xipu He, Li Liu, Xuetang Xu, Yuanjin Xu, Fan Wang, Peican Chen, \\ Liting Zheng, Xiang Li, Yipin Wang, Hong Yang \\ College of Chemistry and Chemical Engineering, Guangxi University, Nanning 530004, China.
}

\begin{abstract}
Owing to the rapid development of new industries, new technologies and new forms of business, the chemistry specialty of Guangxi University is reformed according to emerging engineering education (3E) project, and featured with close combination with local economic and social development. In this paper, the specialty of chemistry actively explores the combination of "science and education", "the base of the master", and "school enterprise" via the revision of the professional training program. The course content is reformed, and the characteristic talent training is emphasized, which is of guiding significance for characteristic direction construction of chemistry specialty with $3 \mathrm{E}$ concepts.
\end{abstract}

Key Words: Chemistry majors; Emerging engineering education; Teaching reform; Innovation practice

随着全球新一轮科技革命和产业变革的蓬勃兴起, 学科和学科之间、科学和技术之间、自然科 学和人文社会科学之间日益呈现交叉融合趋势。产业升级和经济结构调整不断加快, 尤其是人工智 能、物联网、大数据等新技术的融合应用, 需要大量高素质技能人才和高层次创新人才, 传统的人 才培养模式难以满足新兴产业和未来产业的发展需求 ${ }^{[1]}$ 。新工科是基于国家战略发展新需求、国际 竞争新形势、立德树人新要求提出的工程教育改革方向。教育部2016年提出 “新工科” 概念, 2017年

收稿: 2021-10-14; 录用: 2021-10-18; 网络发表: 2021-10-21

“通讯作者, Email: zhouliyatf@163.com

基金资助: 2018-2022年教育部高等学校化学类专业教学指导委员会教学研究与实践项目(H20200512); 广西高等教育本科教学改革工程项目 (2021JGZ104) 
启动 “新工科” 建设, 推动形成了 “复旦共识” “天大行动” 和 “北京指南”, 凝聚了 “新工科” 建 设的广泛共识, 产生了积极的社会影响。“复旦共识” 围绕对 “新工科” 的认识和理解, 明确了 “新 工科” 建设的战略意义和核心理念; “天大行动” 明确要坚持问题导向, 做到 “六问”: 问产业需求 建专业、问技术发展改内容、问学生志趣变方法、问学校主体推改革、问内外资源创条件、问国际 前沿立标准。“北京指南” 发布了 “新工科” 研究与实践项目指南, 提出 “更加注重理念引领、更加 注重结构优化、更加注重模式创新、更加注重质量保障、更加注重分类发展”[2]。

化学类专业属于理工融合专业, 是最具活力和创造性的中心学科之一, 是支撑生命、材料、能 源、环境、医药等众多学科和支柱产业、高精尖技术发展的上游学科 ${ }^{[3]}$ 。为有效将化学研究的创新性 成果及时转化为生产技术和生产力, 增强人才培养对其他学科和产业发展的支持力度, 需适时调整 化学学科人才培养的导向, 通过拓展学生的学科视野, 增强科学素养培养, 提升研究能力、应用开 发能力和技术推广能力, 使学生以化学的观点和方法去观察、思考和解决重大基础性、挑战性问题, 从应用需求出发开发新原理、新方法、新物质、新材料。一方面解决化学新技术的应用转化问题, 另一方面为解决能源、生命、环境等学科领域的重大技术难题提供突破口, 是推进新技术、新产业、 新业态发展的重要基础 ${ }^{[4-7]}$ 。

广西大学是广西办学历史最悠久、规模最大的综合性大学, 是广西唯一的国家 “211工程” 建设 学校, 世界一流学科建设高校, 教育部和广西壮族自治区人民政府 “部区合建” 高校。自治区党委 政府先后批准印发《广西大学综合改革试点方案》《广西大学推进一流大学和一流学科建设方案》 和《“部区合建” 广西大学实施方案》支持广西大学教育教学改革实验与探索。地方经济的快速发展 离不开科技和人才的支持, 广西大学的化学类专业包含化学和应用化学两个专业, 以 “立足广西优 势资源, 瞄准化学发展趋势, 培养创新复合人才” 为办学指导思想, 针对药用植物、松香松节油等 广西天然优势亚热带植物资源, 锰和稀土等广西丰富矿产资源, 在天然有机化学、纳米材料化学、 分析化学和催化化学等领域开展研究并建设课程群。本文主要介绍了广西大学化学类专业在新工科 背景下, 紧密结合区域和地方重大战略需求, 通过调整专业培养目标、优化教学体系和教学模式, 积极探索 “校企、科教、本硕” “三结合” 的人才培养模式改革过程中所做的工作及思考, 推动具有 鲜明区域特征的化学类专业特色化发展。

\section{1 “新工科” 背景下化学类专业创新型人才培养改革的必要性 \\ 1.1 “新工科” 背景下化学类专业创新型人才培养改革的理念}

以 “新工科” 为契机, 广西大学化学类专业面向未来新技术、新产业、新业态发展, 进一步明 确专业发展定位, 强化专业特色, 积极探索 “校企、科教、本硕” “三结合” 的人才培养模式。增强 人才培养对其他学科和产业发展的支持力度, 针对所对应行业的形态和内涵变化, 调整和改革化学 类专业人才培养模式、教学内容体系, 突出行业特色, 建立并完善化学化工理工融合型人才培养体 系, 使之更加适应行业产业发展的需要, 培养能够适应和引领新技术、新产业发展的新型化学类专 业 “新工科” 人才。

\section{2 “新工科” 背景下化学类专业创新型人才培养面临的主要问题}

1) 专业教学理念和人才培养机制有待进一步完善。作为具有理工融合特色的化学类专业, 化学 教学与前沿学科交叉不够; 与行业、企业和地方开展政产学研用协同育人的机制不够健全, 与地方 经济社会发展的结合还不够紧密。

2) 人才培养模式和教学内容方法有待优化和提升。知识体系中缺少信息技术、物联网、大数据、 人工智能等新技术元素, 知识更新不足, 高端发展能力不强, 学生的研究能力、工程设计能力、指 导和管理生产的能力不强。

3) 人才培养面向世界、融入世界的国际化还不够。在吸引国际学术大师参与学生培养、选派优 秀学生访学交流, 推动学生接触世界科学文化研究最前沿等方面还有待提升。 


\section{2 新工科改造的主要举措和成效}

\section{1 “校企” 结合, 主动适应地方经济发展需求}

学院紧紧围绕 “为谁培养人、培养什么人、怎样培养人” 这个核心问题, 落实立德树人根本任 务, 围绕学校培养新时代有社会责任、有法治意识、有创新精神、有实践能力、有国际视野的 “五 有” 领军型人才的培养目标, 主动适应地方经济发展需求, 加强与柳州化工股份有限公司、广西田 园生化股份有限公司等行业企业的对接, 聘请企业技术专家、工程技术人员, 与高校专业带头人、 骨干教师共同组建化学类专业教学指导委员会, 共商人才培养方案, 在课程设置、实习实践、毕业 设计等环节与企业深度融合。通过聘请企业兼职导师到校授课、学生到企业现场教学、举行教学研 讨会等方式, 积极探索校内课堂教学、校内外实践教学和企业合作培养等多种培养模式, 在 “化工 安全与环保” “新型分离技术” 等课程的教学中进行校内外合授, 取得了良好的教学效果。以学院与 农垦明阳生化公司共建的国家级工程实践教育中心为基础, 促进理论与实践结合, 强化学生动手能 力和创新能力的培养, 建设多层次、立体化的联合实习基地, 构建理论教学与工程实训并重的一体 化人才培养体系。构建理论教学与工程实训并重的一体化人才培养体系。

\section{2 “科教” 融通, 将科研成果转化为教学内容}

进一步修订化学类专业和创新人才培养方案, 促进学科交叉和跨界知识融合, 强化数学、物理、 化学基础知识, 拓展和深化化学与化工、生命、材料、医药等学科专业的交叉融合, 开设纳米材料 化学、功能高分子材料、生物有机化学等课程, 促进理工结合、基础和应用等学科专业复合, 将仿 生材料化学、新能源化学、智能材料等前沿理论和技术引入化学专业教学体系, 强化研究的综合性 和问题导向性。推动学院的国家级、区级重点实验室等科研平台向本科生开放共享, 鼓励教师积极 改变教学方法, 通过课前预习、翻转教学、课堂讲解、线上线下交流讨论等方式, 将现代信息技术 全面深度地融入教与学的全过程, 优化教学内容, 提升学业深度和难度, 构建研究型课程体系。针 对广西的天然优势资源和化学化工行业的需求情况, 在化学类专业中设计天然有机化学、高分子化 学和无机功能材料化学等方向并建设课程群, 开设精细化学品化学、聚合物结构与性能等具有明显 应用特色的课程, 构建包含研讨课、案例分析课、前沿讲座课的研究型课程体系。通过将广西优势 资源与教师科研成果结合, 发展特色实验项目 “荧光标记探针制备及成像虚拟仿真实验”, 并进一步 开发交互性好的虚拟仿真实验项目, 强化学生动手能力和创新能力的培养。探索开设导师课程, 以 鼓励学生参加 “大学生创新创业训练计划” 项目为抓手, 导师对学生的人生观、价值观、学习方法 和课题研究等方面进行直接的指导, 培养并训练学生积极动手、善于思考的能力, 促进良好教风和 学风的建设。

\section{3 “本硕” 贯通, 强化学科基础与交叉知识融合}

强化学科交叉和理工融合, 在学院内开设了跨专业创新人才培养实验班(创培班), 从化学类专 业和化学工程与工艺专业中选拔学生, 优化学生遴选和动态管理机制, 实施宽口径的大类培养, 强 化科学领域基础知识与能力的培养, 培养学科基础扎实、具有较强科学素养的化学化工类研究型 人才。同时, 鼓励优秀学生参加学校开设的跨学院、跨学科的物质科学创新人才培养实验班, 强化 基础知识与能力的培养, 培养在物理、化学、材料、环境等特定科学领域交叉融通、具有较强科学 文化素养的拔尖创新人才。学生修读完成相同专业核心课程, 可自主选择创培班覆盖的专业就读, 根据本校研究生专业方向, 进行本硕贯通或本科直博一体化培养。推行本科生导师制, 为创培班学 生安排导师, 鼓励学生进入导师团队, 开展科研工作。在导师指导下制定个性化培养方案, 学生参 与导师的科研活动, 并在导师的指导下选修研究生的学位课程, 实现学生学习能力、研究能力、创 新能力提升。加强专业教育与思政教育的有机融合, 将价值引领融入知识传授和能力培养的 “课程 思政” 教学模式, 注重在专业课程教学中引导学生树立正确的世界观、人生观、价值观, 建立专业 自信, 培养学生求真务实、开拓进取的科研精神。 


\section{4 注重质量, 完善学院教学质量保障体系}

学院教学指导委员会确定化学类专业人才培养目标, 进行学院教学质量保障体系顶层设计, 确 立和优化理论、实验等课程教学环节的质量标准和要求。完善院、系、教学团队三级教学质量保障 和监控体系, 形成学生、同行、专家、教务管理等多维度评教评学体系, 通过访谈、学生评教、教 师评学、教学研讨等方式, 全程、常态化保障教学质量。定期对毕业生的就业单位和校友进行跟踪 访谈、交流, 根据用人单位和校友的反馈, 形成学生培养质量的外部评价。根据教学质量内部与外 部评价结果, 提出教学改进措施, 持续改进教学质量。

\section{5 整合资源, 加强交流合作和视野拓展}

积极拓展联合培养、交换生、校友等资源, 通过邀请优秀校友返校开设 “校友论坛”、学生走进 校友企业、建立校友企业实习实践基地等方式, 充分发挥优秀校友的榜样示范作用, 加强专业自信 心和自豪感，充分激发学习热情。在学院校友已设立的 “思远笃行奖学金” “庞博奖学金” 的基础上, 继续增大校友专项奖学金的支持力度, 为学生潜心科学研究和研学交流提供坚实保障。坚持开放办 学, 注重追踪化学发展趋势, 开设反映现代化学成就和进展的课程, 如超分子化学、应用化学专题 (全英文)等。通过国际学术交流、联合培养、短期访学等多种交流形式, 利用优质资源拓展学生的国 际视野和交流能力。定期邀请校内外有影响力的学者为学生开展学术讲座活动、举办读书报告会等, 多维度参与学生培养; 选派优秀学生参加国际学术交流和访学实践, 拓宽学生知识面和学术视野, 培养学生的专业前沿意识, 为学生融入国际先进学术群体创造条件。

\section{3 结语}

“新工科”背景下化学类专业创新型人才培养紧紧围绕立德树人, 全面落实人才培养中心地位, 强化专业特色, 探索了 “校企、科教、本硕” “三结合” 的人才培养新模式, 使专业人才培养能够 更好地适应新技术、新产业、新业态的发展需要, 以有效对接服务区域社会经济社会发展及行业发 展需求, 构建了与广西经济社会发展相适应的 “新工科”化学类本科人才培养体系。

\section{参 考 文 献}

[1] 习近平. 求是. 2021, No. 6, 1 .

[2] 吴爱华, 杨秋波, 郝杰. 高等工程教育研究, 2019, No. 1, 1.

[3] 张树永, 朱亚先, 霍冀川, 宋丽娟, 徐华龙, 郑兰荪. 大学化学, 2020, 35 (10), 1.

[4] 张树永, 朱亚先. 中国大学教学, 2018, No. 3, 25.

[5] 朱日龙, 楚宗霖, 黄中原, 邹雨芹, 张小华, 周海晖, 蔡双莲, 杜翠翠, 李永军, 刘娅莉. 大学化学, 2020, 35 (10), 82.

[6] 吕洲, 朱倩倩, 李群, 王宗花, 毕赛. 大学化学, 2020,35 (10), 87.

[7] 王成云, 张文清, 朱为宏. 大学化学, 2020, 35 (10), 65. 